\title{
The Production of a Monoclonal Antibody That Blocks the Action of a Neurite Outgrowth-promoting Factor
}

\author{
W.D. MATTHEW AND P.H. PATTERSON* \\ Department of Neurobiology, Harvard Medical School, Boston, Massachusetts 02115
}

\begin{abstract}
How growing axons are guided to their targets has been the subject of much speculation. A popular hypothesis is that there are macromolecules in the extracellular matrix (ECM) or on the surfaces of other cells that form pathways for axon guidance. Such molecular signals could act via a number of different mechanisms. One way of directing neurite growth is by providing a very adhesive surface for growth cone attachment (Letourneau 1975). There are, however, more elaborate ways in which such molecules could function. For instance, the extracellular signals could be recognized by surface receptors on the axons, or be internalized where they could influence the rate or direction of neurite growth. Nerve growth factor (NGF), for instance, can act as a chemoattractive agent by binding to growing neurites (Gundersen and Barrett 1980; Claude et al. 1982). A variety of cells, both nonneuronal and neuronal, might synthesize guidance molecules. Clearly, all target cells are candidates for synthesizing these factors, as was demonstrated for NGF (Ebendal et al. 1980; Korsching and Thoenen 1983). If neurons were to secrete guidance or adhesion molecules, and deposit them in an ECM along their axonal length, then these factors would be ideally localized for directing regrowth of neurites after axotomy. In addition, there is evidence that neuronal surfaces contain molecules that are adhesive for other neurites or growth cones (Rutishauser et al. 1978; Bentley and Keshishian 1982; Taghert et al. 1982).
\end{abstract}

Cell culture has proven to be a useful tool for identifying molecules that influence the rate or direction of neurite growth. Several groups have described factors present in conditioned media (CM) that bind to polycationic substrata and stimulate neurite outgrowth from peripheral neurons in culture (Collins 1978; Adler et al. 1981; Coughlin et al. 1981). This biological activity appears to be synthesized by many kinds of primary cells and cell lines (Adler et al. 1981). The neuritepromoting factor contained in bovine corneal endothelial cell CM has been partially characterized, and the activity is associated with a heparan sulfate proteoglycan (Lander et al. 1982). In the hope of studying the distribution and function of such molecules in vivo, several groups have initiated an immunological approach. Coughlin and Kessler (1982) have recently developed a polyclonal antiserum to a partially purified $\mathrm{CM}$ factor. This antiserum blocks neurite outgrowth in

\footnotetext{
*Present address: Biology Division, California Institute of
} Technology, Pasadena, California, 91125. vitro. Although it is probable that this antiserum contains antibodies directed against the functional site of the active molecule, it is likely that such antisera also contain antibodies directed at contaminants in the preparation.

An alternate approach is to use hybridoma methods to develop highly specific antibodies to impure material. Matthew and colleagues $(1982,1983)$ have described five monoclonal antibodies-pg3, pg15, pg22, $\mathrm{pg} 31$, and $\mathrm{pg} 42$ - that precipitate a heparan sulfate proteoglycan from pheochromocytoma (PC12) cell CM and, in doing so, deplete $\mathrm{CM}$ of its ability to induce rapid neurite outgrowth. However, when these antibodies are adsorbed to $\mathrm{CM}$-coated dishes, there is no inhibition of the outgrowth-promoting activity. Therefore, it is unclear if the heparan sulfate proteoglycan is directly responsible for promoting neurite growth or if it is merely required to adsorb an associated molecule (the active factor) to the polycationic culture surface. Obviously, if a monoclonal antibody could be developed that directly blocked the neurite-promoting activity of the CM factor, it would be an appropriate probe for (1) studying the biochemical properties of this factor, (2) determining if various CM preparations contain identical molecules, (3) localizing the activity in situ throughout development, and (4) determining the mechanism by which this molecule elicits neurite outgrowth. With these goals in mind, we have developed a monoclonal antibody-INO (inhibitor of neurite outgrowth)-which, when adsorbed to CM-coated dishes, blocks the neurite-promoting activity. We describe below the novel method used to produce this antibody and our preliminary results on the biochemical characterization and in situ localization of this activity.

\section{METHODS}

Cell culture and CM preparation. Normal PC12 cells and F3 cells (mutant PC12 cells secreting an altered form of the heparan sulfate proteoglycan that is not able to induce neurite outgrowth [Matthew et al. 1982]) were maintained in $\mathrm{L} 15-\mathrm{CO}_{2}$ medium (Hawrot and Patterson 1979), supplemented with $10 \%$ fetal calf serum and $5 \%$ horse serum. Each cell line was grown in medium containing NGF and serum for 2 weeks and then rinsed thoroughly with serum-free medium. Cells were grown in serum-free medium for 12 hours and rinsed and then fresh medium was added. After 3 days, $500 \mathrm{ml}$ of CM was collected and adsorbed to $20 \mathrm{ml}$ of DEAE-cellulose equilibrated with $150 \mathrm{~mm} \mathrm{NaCl}$. The 
column was washed with $150 \mathrm{mM} \mathrm{NaCl}$, and the neurite outgrowth activity and heparan sulfate proteoglycan were eluted with $1.5 \mathrm{M} \mathrm{NaCl}$ and stored frozen at $-20^{\circ} \mathrm{C}$.

A nonneuronal, fibroblastlike cell line, which was established from primary dorsal root ganglia (DRG) cultures (Matthew 1981), secretes a high concentration of neurite-promoting activity. Cells were grown to confluence in $\mathrm{L} 15-\mathrm{CO}_{2}$ containing $10 \%$ fetal calf serum and rinsed in serum-free medium. The cells were grown for 2 days in serum-free medium, rinsed, and maintained until the medium started to turn acidic (4-8 days). The final collection of conditioned medium was then fractionated on DEAE-cellulose, as previously described.

Assay for inhibition of neurite outgrowth. Glass coverslips were cleaned with concentrated sulfuric acid, rinsed with distilled water and then with $0.1 \mathrm{M}$ $\mathrm{NaOH}$, air-dried, and reacted with aminopropyltriethoxysilane (Sigma) for 3 minutes. After extensive washing with distilled water and then sterile phosphate buffer, coverslips were incubated with $\mathrm{CM}$ overnight at $4^{\circ} \mathrm{C}$. The surface was rinsed thoroughly with fresh culture medium and incubated with hybridoma culture supernatants for 1 hour at room temperature followed by $5-12$ hours at $4^{\circ} \mathrm{C}$. The coverslips were rinsed, and primary sympathetic neurons were plated in $\mathrm{L} 15-\mathrm{CO}_{2}$ medium in the absence of serum. Process outgrowth was assayed between 4 and 12 hours later. In some experiments, the coverslips were UV-irradiated in a laminar flow hood to ensure sterile conditions prior to plating neurons.

Immunization-Cyclophosphamide treatment. A 6-week-old, female BALB/c mouse was immunized intraperitoneally with $10 \mu \mathrm{g}$ of DEAE-fractionated F3 (mutant PC12 cell line) $\mathrm{CM}$ in Freund's complete adjuvant. Two days later, this mouse was injected intraperitoneally with the immunosuppressant drug cyclophosphamide ( $40 \mathrm{mg} / \mathrm{kg}$, Cytoxan, Mead Johnson) in saline. Three weeks after the initial immunization, the spleen was removed, dissociated, and sensitized in vitro with $10 \mathrm{ng}$ of DEAE-fractionated normal PC12 CM. Fusion to NS1 myeloma cells was performed 3.5 days later.

In vitro immunization. Stimulated $\mathrm{T}$-cell-conditioned medium was prepared by incubating washed spleen cells in standard $\mathrm{L} 15-\mathrm{CO}_{2}$ medium (our more recent work uses F12 medium) supplemented with vitamins (Hawrot and Patterson 1979), $5 \times 10^{-5} \mathrm{M}$ 2-mercaptoethanol, $100 \mathrm{U} / \mathrm{ml}$ penicillin, $100 \mu \mathrm{g} / \mathrm{ml}$ streptomycin, $2 \mathrm{~mm}$ glutamine, $6 \mathrm{mg} / \mathrm{ml}$ glucose, $10 \%$ prescreened fetal calf serum (lot \#100361, Sterile Systems Inc., Logan, Utah), and $4 \mu \mathrm{g} / \mathrm{ml}$ Con-A lectin (Sigma \#C2010, grade IV). Cells were plated at a density of $5 \times 10^{6}$ lymphocytes $/ \mathrm{ml}$ in a $75-\mathrm{cm}^{2}$ flask and grown for 48 hours in a $5 \% \mathrm{CO}_{2}$ atmosphere. Cells were centrifuged, and the $\mathrm{CM}$ was adsorbed to approximately $1 \mathrm{ml}$ of swollen Sephadex G-25 to remove the lectin, centrifuged, and finally sterilized by passage through a $0.2-\mu \mathrm{m}$ Millipore filter. This T-cell $\mathrm{CM}$ was diluted with an equal volume of fresh medium (without Con A), and the fetal calf serum was adjusted to $20 \%$ of the total volume. Muramyl di-peptide (Adjuvant peptide, Sigma) was added to this medium at a concentration of $25 \mu \mathrm{g} / \mathrm{ml}$. The spleen from the mouse that had been primed and treated with cyclophosphamide was dissociated and plated into $10 \mathrm{ml}$ of the diluted T-cell medium, which contained $10 \mathrm{ng}$ of antigen from PC12 cell $\mathrm{CM}$. The cells were plated at $10^{7}$ cells $/ \mathrm{ml}$ in a $25-\mathrm{cm}^{2}$ tissue culture flask (Corning \#25100) stood upright and incubated for 3.5 days. In our more recent work, we double the culture volume with fresh medium (without antigen) each day.

${ }^{35} S$ labeling of cells. The DRG nonneuronal cell line was grown to confluence in $75-\mathrm{cm}^{2}$ flasks in L15- $\mathrm{CO}_{2}$ medium containing $10 \%$ fetal calf serum and then maintained for 2 weeks in serum-free $\mathrm{L} 15-\mathrm{CO}_{2}$. Cultures were briefly rinsed in sulfate-free $\mathrm{L} 15-\mathrm{CO}_{2}$, and each flash was incubated in $10 \mathrm{ml}$ of $\mathrm{L} 15-\mathrm{CO}_{2}$ containing $1 \mathrm{mCi}$ of carrier-free $\left[{ }^{35} \mathrm{~S}\right]$ sulfate (ICN, Irvine, Calif.). After 7 days, CM was recovered and stored on ice; experiments were completed within 6 days. Approximately $1 \%$ of the ${ }^{35} \mathrm{~S}$ counts were excluded from Sephadex G-25.

Sepharose $4 B$ gel chromatography. ${ }^{35}$ S-labeled CM $(5 \mathrm{ml})$ was incubated in solution with $0.5 \mathrm{ml}$ of DEAE (equilibrated with $0.15 \mathrm{M} \mathrm{NaCl}$ ) for 30 minutes at room temperature. The DEAE was packed into a column and washed extensively with Hank's buffer (GIBCO) followed by $5 \mathrm{ml}$ of $\mathrm{Ca}^{++}-\mathrm{Mg}^{++}$-free Hank's buffer. The INO antigen was eluted with concentrated $\mathrm{Ca}^{++}-\mathrm{Mg}^{++}$-free Hank's buffer $(0.5 \mathrm{M}$ $\mathrm{NaCl}$ ). Fractions were collected, an aliquot of each was counted for ${ }^{35} \mathrm{~S}$, and appropriate samples were pooled. Solid guanidine $\mathrm{HCl}$ was added to bring an aliquot to a concentration of $6 \mathrm{M}$. This sample was stored overnight on ice and chromatographed on a $1-\mathrm{cm} \times 26-\mathrm{cm}$ column of Sepharose 4B equilibrated with $\mathrm{Ca}^{++}-\mathrm{Mg}^{++}$-free Hank's buffer. Single drops $(50 \mu \mathrm{l}$ each) were collected into individual wells of flexible microtiter dishes. Sequential samples were assayed with either a solid-phase radioimmunoassay (Klinman 1972; Matthew 1981) for binding of INO, pg42, or a control monoclonal antibody that does not bind this material, or counted for ${ }^{35} \mathrm{~S}$ in a scintillation counter. Each value cited is the average of two samples. The void volume and the total volume for this column was determined using Blue Dextran and $\left[{ }^{35} S\right]$ sulfate.

Immunocytochemical localization. Unfixed superior cervical ganglia were frozen on dry ice, and $10-\mu \mathrm{m}$ sections were cut on a cryostat. Sections were dried on glass slides at room temperature and then frozen and thawed to facilitate penetration. Sections were incubated in INO hybridoma culture medium for 30 minutes at $4^{\circ} \mathrm{C}$ and then washed twice with phosphate-buffered saline (PBS). Rhodamine-coupled $F(a b)_{2}$ fragments of 
goat anti-mouse immunoglobulin (Cappel, Inc.) were preincubated for 30 minutes at $4^{\circ} \mathrm{C}$ in a $1: 1$ dilution with adult rat serum. This solution was diluted 1:100 with $\mathrm{L} 15-\mathrm{CO}_{2}$ medium containing $1 \% \mathrm{FCS}$ and incubated on the sections for 30 minutes at $4^{\circ} \mathrm{C}$. After two washes with PBS, the slides were mounted in PBSglycerol (1:1) and viewed with a Zeiss inverted microscope equipped with Epi-illumination and a rhodamine filter set using a $40 \times$ objective. Fluorescent exposures were for 30 seconds using Ilford HP5-135 film. Omission of the INO antibody or incubation with other monoclonal antibodies yielded minimal staining.

6-Hydroxydopamine treatment. Adult rats were injected intraperitoneally with $100 \mathrm{mg} / \mathrm{kg}$ 6-hydroxydopamine (in $0.9 \% \mathrm{NaCl}$ plus $0.5 \mathrm{mg} / \mathrm{ml}$ ascorbic acid). This injection was repeated 12 hours later and twice again 7 days later (Finch et al. 1973). Glyoxylic acid analysis of catecholamine fluorescence in sympathetic axons in the irides confirmed that 12 days after the initial injection, the sympathetic innervation was virtually eliminated.

\section{RESULTS}

Even though the five anti-heparan sulfate proteoglycan antibodies capable of precipitating the neurite-promoting activity from $\mathrm{PC} 12 \mathrm{CM}$ did not directly block neurite outgrowth when bound to CM-coated culture substratum (Matthew et al. 1982), we were optimistic that a blocking antibody could be produced. We found that both the neurite-promoting activity and the heparan sulfate proteoglycan antigen could be concentrated on DEAE-cellulose and eluted with high salt. Therefore, we produced monoclonal antibodies from mice immunized with this heparan sulfate proteoglycan preparation and screened supernatants for binding to this material. After generating 138 monoclonal antibodies that bound the CM factor but did not block function, we decided to use a new approach. A mouse was immunized with an inactive heparan sulfate proteoglycan preparation obtained from a mutant PC12 cell line (F3; Matthew et al. 1982) to initiate a response to the nonfunctional, immunodominant determinants in the CM. Two days later, an immunosuppressant drug was injected. Our strategy was to kill the lymphocytes stimulated by these determinants. Three weeks later, the spleen was dissociated and immunized in vitro with an active CM preparation from normal PC12 cells. The rationale for using the in vitro immunization procedure was based on the idea that there is less immunosuppression in culture (discussed by Reading 1982). The cells were fused to myeloma cells and plated at a clonal dilution. From this fusion, 21 hybridoma clones grew and 5 showed clear binding to $\mathrm{CM}$ in a radioimmunoassay. We tested these five antibodies for their ability to directly block the neurite-promoting activity of CM bound to the substratum. Figure 1 shows an example of an assay where the INO antibody is able to block the outgrowth activity. Unlike the 143 antibodies generated by conventional immunizations, none of which could block the stimulated neurite outgrowth, four of the five antibodies developed with this new procedure did block neurite growth in vitro. One of these hybridoma lines, INO, has been cloned, and we are beginning to study the properties of the antigen recognized by this antibody.

Our best source for the neurite-promoting activity is a nonneuronal cell line isolated from a primary culture of newborn rat DRG cells (Matthew 1981). The five original monoclonal antibodies that recognize heparan sulfate proteoglycan, and precipitate the neurite-promoting activity from $\mathrm{CM}$, bind the surface of these cells in culture (Matthew 1981). The origin of this cell line is uncertain. However, the five anti-heparan sulfate proteoglycan antibodies stain pericytes and mesangial cells around capillaries in situ (N. Dekker, pers. comm.). The cell line isolated from DRG secretes a large amount of the INO antigen as well as the neuritepromoting activity. Therefore, we decided to study the antigen synthesized by these cells. The neurite-promoting activity appears to be associated with a heparan sulfate proteoglycan fraction, as was the case for the activity released by bovine corneal endothelial cells (Lander et al. 1982). Since cells incorporate ${ }^{35}$ S $]$ sulfate primarily into proteoglycans (Okayama et al. 1976; Hassell et al. 1980), we labeled the DRG accessory cell line with radioactive sulfate and found that the INO antigen coeluted from DEAE-cellulose with a peak of ${ }^{35} \mathrm{~S}$-labeled material between $0.3 \mathrm{M}$ and $0.5 \mathrm{M} \mathrm{NaCl}$ (data not shown). We chromatographed this DEAE fraction on Sepharose 4B. Both the pg42 (an antibody that binds the core protein of a heparan sulfate proteoglycan [Matthew 1981] and can precipitate the neurite-promoting activity but not block it directly) and INO immunoreactivity coeluted with the majority of ${ }^{35} \mathrm{~S}$-labeled material that had an apparent molecular weight of approximately $10 \times 10^{6}$ (data not shown). Therefore, it seems likely that the INO determinant is either part of the same heparan sulfate proteoglycan molecule recognized by the original monoclonal antibodies (Matthew 1981) or associated with this heparan sulfate proteoglycan complex. To assess the latter possibility, the sulfate-labeled DEAE fraction was extracted in $6 \mathrm{M}$ guanidine to dissociate the proteoglycan complex and then chromatographed on Sepharose 4B (Fig. 2). The elution profile of ${ }^{35} \mathrm{~S}$ label reflected a very heterogeneous size distribution. The binding pattern of the pg42 antibody shows that the heparan sulfate proteoglycan is codistributed with the sulfate label. The heterogeneous size distribution could be caused by incomplete dissociation of the complex or by reaggregation of the proteoglycan during chromatography in physiological buffer.

We see that the INO determinant elutes from this column with a different profile from the proteoglycan. The INO antibody binds only to material eluting with a molecular weight of approximately $10 \times 10^{6}$. If the INO antibody does bind to a heparan sulfate proteoglycan, then it recognizes either a unique conformation or 

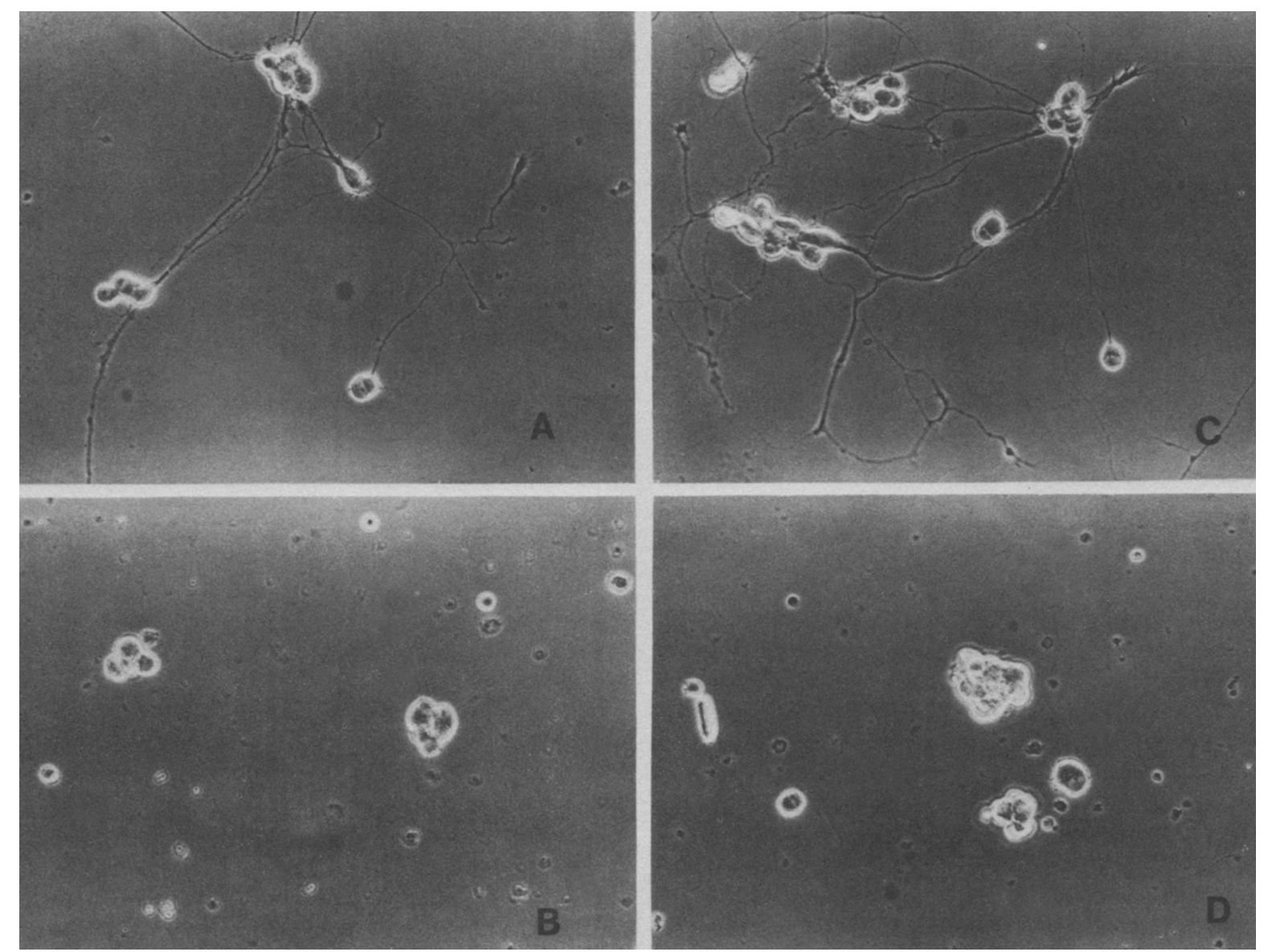

Figure 1. Substrata were prepared as described in Methods using CM from the dorsal root ganglia-derived cell line. In $A$, neurons were plated on CM-treated coverslips that were not incubated with hybridoma fluid. In $B$, the $C M$ was omitted. $C$ shows neurons plated on CM-coated coverslips that were incubated with one of the nonfunction-blocking antibodies which recognizes the heparan sulfate proteoglycan (pg22), and in $D$ the substrate was incubated with INO antibody. Neurons were photographed $10 \mathrm{hr}$ after plating.

determinant on a subpopulation of heparan sulfate proteoglycan molecules. Alternatively, the INO determinant may be on a molecule tightly associated with the heparan sulfate proteoglycan, or possibly the determinant is defined by a conformation resulting from the interaction of an associated molecule and the heparan sulfate proteoglycan.

Since the INO antibody recognizes a determinant that plays a role in the stimulation of neurite outgrowth in vitro, it is of interest to determine the localization of this molecule in vivo. Using indirect immunofluorescence techniques, we have begun to examine the distribution of INO antibody binding. The most striking binding seen so far is associated with neural elements, particularly during development. For instance, fluorescent staining is seen in the neonatal rat superior cervical ganglion (SCG) (Fig. 3A). The extreme sensitivity of the antigen to fixation has thus far prevented a detailed analysis of the distribution of antigen with the neonatal ganglion. In the clearest cases, however, staining appears to be associated with neuronal cell bodies. That this INO binding is associated with neurite outgrowth is supported by the observation of bright staining in newborn and 14-day SCG (Fig. 3A,B). However, stain- ing is greatly diminished by 21 days of development (Fig. 3C) and is rarely seen in the adult ganglion (Fig. 3D). Thus, the detection of immunoreactivity is correlated with the time of axonal growth.

To examine this correlation further, the axons of adult noradrenergic sympathetic neurons were heavily damaged by intraperitoneal injections of 6-hydroxydopamine, a toxic catecholamine congener. In the adult, neuronal cell bodies survive this treatment and regrow axons back into targets (Finch et al. 1973). At the time this regrowth is occurring (12 days after the first injection), the INO staining is apparent in the adult SCG (see Fig. 3E-I). Although a detailed time course has not yet been established, the staining appears to be much heavier at 12 days postinjection than at either 9 days or 2 months after injection. It is interesting that in sections with particularly good tissue preservation, the antibody appears to bind to the neuronal nucleus (Fig. 3E-H).

\section{DISCUSSION}

Using standard immunization procedures, we developed 138 antibodies that recognize the neurite out- 


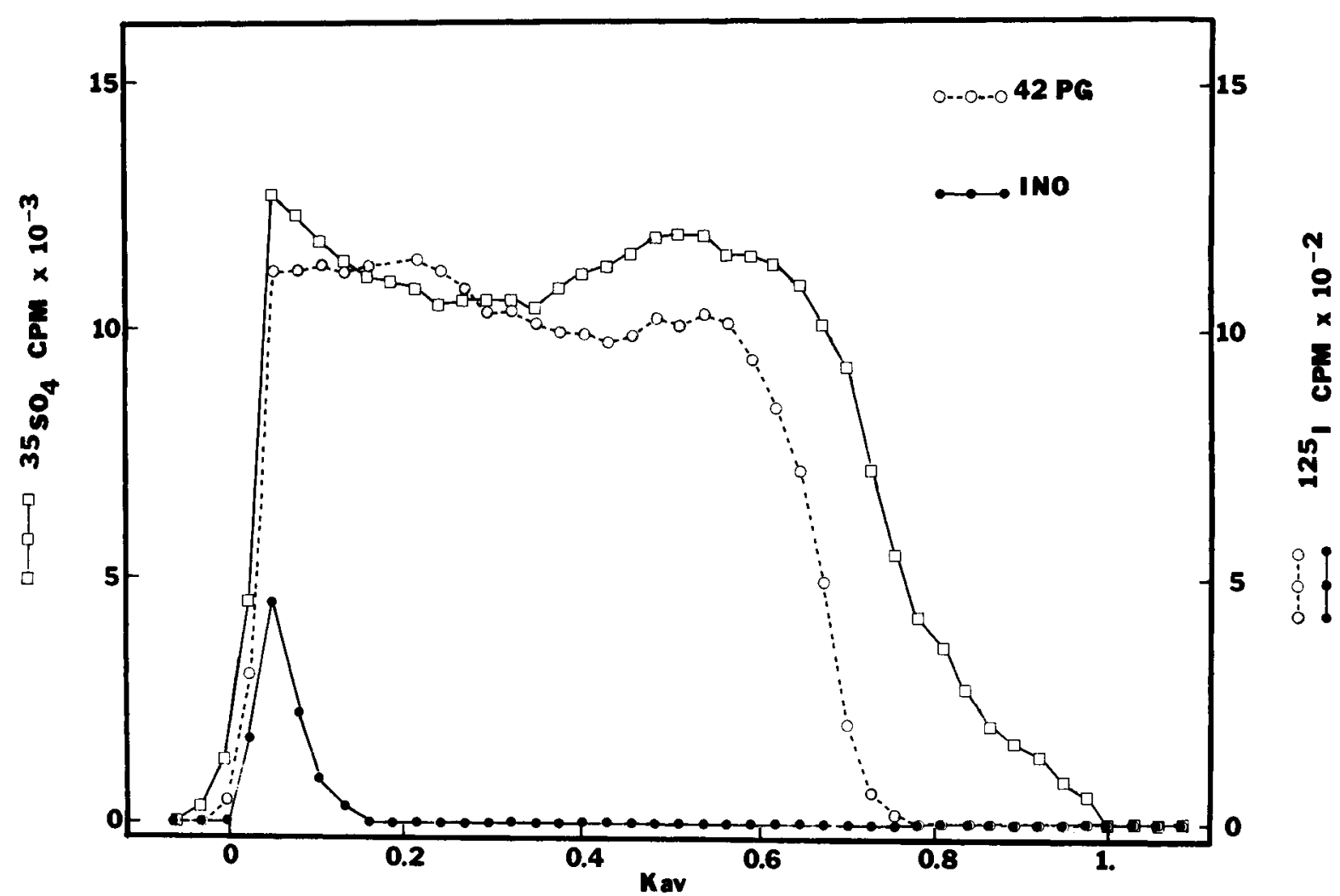

Figure 2. The DRG nonneuronal cell line was grown in $\left.{ }^{35} \mathrm{~S}\right]$ sulfate to label proteoglycans. The $\mathrm{CM}$ was fractionated on DEAE, incubated in $6 \mathrm{M}$ guanidine, and chromatographed on Sepharose $4 \mathrm{~B}$ in $\mathrm{Ca}^{++}-\mathrm{Mg}^{++}$-free Hank's buffer. Sequential drops were assayed for binding of INO, pg42, and ${ }^{35} \mathrm{~S}$. (Kav = elution volume - void volume/total volume - void volume.)

growth-stimulating preparation, but, like the five original antibodies to the heparan sulfate proteoglycan (Matthew et al. 1982, 1983), none can directly block the neurite-promoting activity in culture. We feel the immunological procedures we designed to minimize immunodominance and suppression were crucial in developing the function-blocking antibody. Using this procedure, four out of five antibodies against the $\mathrm{CM}$ were capable of blocking function. Our strategy of eliciting an immune response to uninteresting determinants, followed by an immunosuppressant drug to destroy the lymphocytes responsible for this reaction, should be of general usefulness. It seems likely that we did not need to use a mutant heparan sulfate proteoglycan in order to initiate a response to uninteresting determinants-our standard immunizations with heparan sulfate proteoglycan did not appear to elicit a response to the functional determinant. Using a variety of immunogens, we currently are testing this procedure for its ability to generate monoclonal antibodies to unique determinants.

Having developed a monoclonal antibody that blocks the function of the neurite-promoting factor, we are in a position to characterize this molecule. Our initial findings argue that if the heparan sulfate proteoglycan is not directly responsible for the outgrowth activity, it is certainly tightly associated with this factor. If the INO antibody does bind the heparan sulfate proteoglycan, it must recognize an epitope unique to the complexed molecule. It is still possible, however, that the INO de- terminant is not on the heparan sulfate proteoglycan itself but on an associated molecule that is either very tightly coupled to the heparan sulfate proteoglycan or adopts a unique conformation in the aggregate. A key experiment that will help resolve this question is to determine whether the INO determinant is sensitive to heparinase treatment (Lander et al. 1982). Of course, if the antibody recognizes a particular conformation composed of both the heparan sulfate proteoglycan and an associated molecule, then we will not be able to disrupt the complex without destroying antigenicity.

Since this antibody blocks neurite outgrowth, it is the most relevant probe for localizing the activity in situ. INO binding is found in the developing SCG, as was the binding of the anti-proteoglycan antibodies originally developed by Matthew and Reichardt (Greif and Reichardt 1982). Using immunohistochemistry and radioimmunoassay with the original anti-proteoglycan antibodies, Greif and Reichardt determined that the proteoglycan accumulates in the SCG throughout development and reaches a maximum level in the adult. The INO determinant differs in that it is present in neonates but declines during development as axonal outgrowth ceases. However, when adult sympathetic neurons are axotomized with 6-hydroxydopamine, the INO binding reappears in the adult SCG during the period of axonal regeneration. In these preliminary studies, binding has not been detected in sympathetic target tissues.

A very surprising feature of the staining in adult neu- 

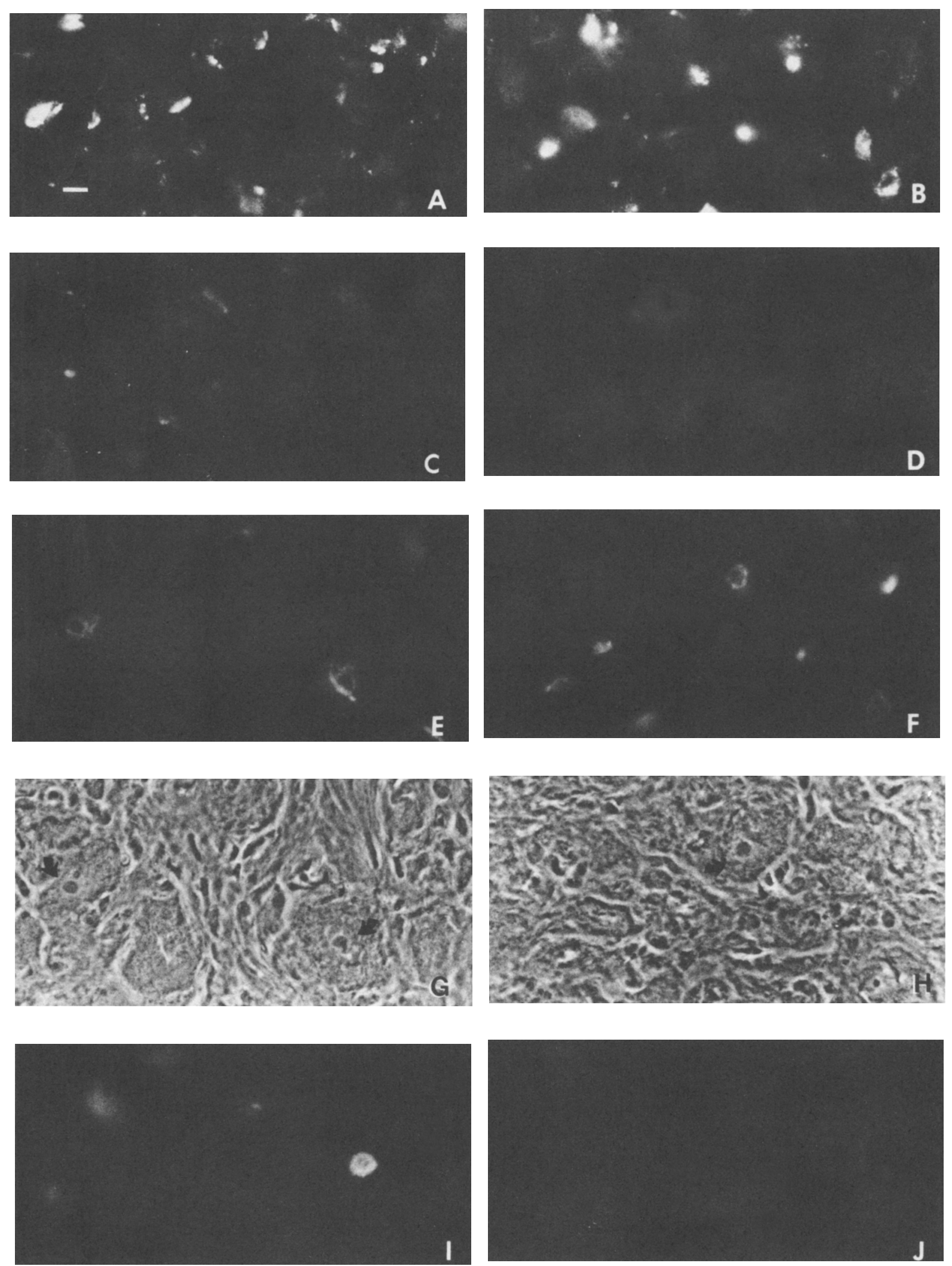

Figure 3. Indirect immunofluorescence was used to localize the INO antigen in superior cervical ganglia from newborn $(A)$, 14-day $(B), 21$-day $(C)$, and adult $(D)$ rats. $E$ and $F$ show binding to sections of superior cervical ganglia from 6-hydroxydopamine-treated adult animals and $G$ and $H$ are the corresponding phase photographs. The arrows indicate nuclear staining. Another example of staining in the axotomized SCG is shown in $I$. $J$ illustrates a control section of a 6-hydroxydopamine-treated animal that was incubated with rhodamine-coupled second antibody only. Bar in $A, 20 \mu \mathrm{m}$; all photographs are taken at the same magnification. 
rons is the localization within neuronal nuclei. Why should a heparan sulfate proteoglycan complex be localized in the nucleus? It is possible that some portion of the extracellular neurite outgrowth molecule is internalized during growth and transported to the nucleus. Another possibility is that we are observing cross-reactivity of the INO antibody with an entirely different molecule. It will therefore be important to characterize the antigen in the developing SCG and in axotomized adult neurons, as well as in the active CM. If the binding we have detected thus far does represent cross-reactivity, it is quite a coincidence that the cross-reactivity molecule only appears during axonal outgrowth both in developing and in adult neurons. If the molecule detected in the nucleus does turn out to be the heparan sulfate proteoglycan-associated activity, its mechanism of action could be related to differential gene action, as opposed to direct mediation of neurite adhesion which appears to be the case with N-CAM, for instance (Rutishauser and Edelman 1978).

Henke-Fahle and Bonhoeffer (1983) have recently developed a monoclonal antibody that inhibits axonal outgrowth from chick retinal explants but does not affect axon growth from the peripheral neurons. Any relationship between this molecule and the activity that is associated with the heparan sulfate proteoglycan factor in the periphery will be elucidated only when each has been purified and characterized. We feel that an immunological approach to neurite growth-promoting factors will be crucial in understanding the role of these molecules in development.

\section{ACKNOWLEDGMENTS}

We gratefully acknowledge the important contribution to this work by Story Landis, Doreen McDowell, Elizabeth Silvestro, Gerri Spencer, and Vivien Yee. The work was supported by the NINCDS, the Jane Coffin Childs Memorial Fund, and the Rita Allen and McKnight Foundations.

\section{REFERENCES}

Adler, R., M. Manthrope, S.D. Skaper, and S. Varon. 1981. Polyornithine-attached neurite-promoting factors (PNPFs). Culture sources and responsive neurons. Brain Res. 206: 129.

Bentley, D. and H. Keshishian. 1982. Pathfinding by peripheral pioneer neurons in grasshoppers. Science 218: 1082 .

Claude, P., E. Hawrot, D.A. Dunis, and R.B. Campenot. 1982. Binding, internalization, and retrograde transport of ${ }^{125}$ I-nerve growth factor in cultured rat sympathetic neurons. J. Neurosci. 2: 431.

COLLINS, F. 1978. Induction of neurite outgrowth by a conditioned-medium factor bound to the culture substratum. Proc. Natl. Acad. Sci. 75: 5210.

Coughlin, M.D. and J.A. Kessler. 1982. Antiserum to a new neuronal growth factor: Effects on neurite outgrowth. J. Neurosci. Res. 8: 289.
Coughlin, M.D., E.M. Bloom, and I.B. Black. 1981. Characterization of a neuronal growth factor from mouse heart-cell-conditioned medium. Dev. Biol. 82: 56.

Ebendal, T., L. Olson, A. Seiger, and K.-O. Hedlund. 1980. Nerve growth factors on the rat iris. Nature 286: 25 .

Finch, L., G. Haeusler, and H. Thoenen. 1973. A comparison of the effects of chemical sympathectomy by 6-hydroxydopamine in newborn and adult rats. Br. J. Pharmacol. 47: 249.

Greif, K.F. and L.F. Reichardt. 1982. Appearance and distribution of neuronal cell surface and synaptic vesicle antigens in the developing rat superior cervical ganglion. J. Neurosci. 2: 843.

Gundersen, R.W. and J.N. Barrett. 1980. Characterization of the turning response of dorsal root neurites toward nerve growth factor. J. Cell Biol. 87: 546.

Hassell, J.R., P.G. Robey, H. Barrach, J. Wilczek, S.I. RENNARD, and G.R. MARTIN. 1980. Isolation of a heparan sulphate-containing proteoglycan from basement membrane. Proc. Natl. Acad. Sci. 77: 4494.

Hawrot, E. and P.H. Patterson. 1979. Long-term culture of dissociated sympathetic neurons. Methods Enzymol. 58: 574 .

HeNKe-FAHLE, S. and F. BonhoefFer. 1983. Inhibition of axonal growth by a monoclonal antibody. Nature 303: 65 .

KLINMAN, N.R. 1972. The mechanism of antigenic stimulation of primary and secondary clonal precursor cells. $J$. Exp. Med. 136: 241.

Korsching, S. and H. Thoenen. 1983. Levels of nerve growth factor in sympathetic ganglia and corresponding target organs of the rat: Correlation with the density of sympathetic innervation. Proc. Natl. Acad. Sci. 80: 3513.

LANDER, A.D., D.K. FuJil, D. Gospodarowicz, and L.F. REICHARDT. 1982. Characterization of a factor that promotes neurite outgrowth: Evidence linking activity to a heparan sulfate proteoglycan. J. Cell Biol. 94: 574.

Letourneau, P.C. 1975. Cell-to-substratum adhesion and guidance of axonal elongation. Dev. Biol. 44: 92.

Matthew, W.D. 1981. "Biochemical studies using monoclonal antibodies to neural antigens." Ph.D. thesis, University of California, San Francisco.

Matthew, W.D., A.D. Lander, R.J. GreEnspan, and L.F. REICHARDT. 1982. A heparan sulfate proteoglycan on the surface of neurons in vivo is associated with a potent inducer of in vitro neurite outgrowth. Soc. Neurosci. Abstr. 8: 834.

Matthew, W.D., K. Greif, L.F. Reichardt, R. GreENSPAN, and A.D. LANDER. 1983. Applications of monoclonal antibodies to studies on neurite growth and synapse formation. In Proceedings of the First International Congress of Neuroimmunology. Raven Press, New York. (In press).

Oxayama, M., M. Pacifici, and H. Holtzer. 1976. Differences among sulfonated proteoglycans synthesized in non-chondrogenic cells, presumptive chondroblasts and chondroblasts. Proc. Natl. Acad. Sci. 73: 3224.

Reading, C.L. 1982. Theory and methods for immunization in culture and monoclonal antibody production. J. Immunol. Methods 53: 261.

Rutishauser, U., W.E. Gall, and G.M. Edelman. 1978. Adhesion among neural cells of the chick embryo. IV. Role of the cell surface molecule CAM in the formation of neurite bundles in cultures of spinal ganglia. J. Cell Biol. 79: 382 .

Taghert, P.H., M.J. Bastiani, R.K. Ho, and C.S. GoodMAN. 1982. Guidance of pioneer growth cones: Filopodial contacts and coupling revealed with an antibody to Lucifer yellow. Dev. Biol. 94: 391 . 


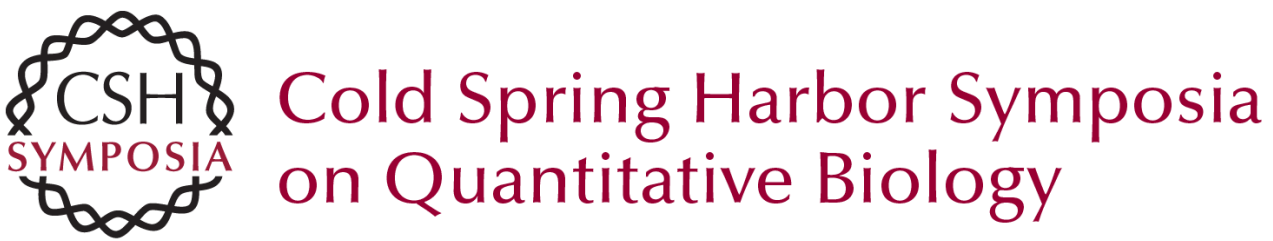

\section{The Production of a Monoclonal Antibody That Blocks the Action of a Neurite Outgrowth-promoting Factor}

W.D. Matthew and P.H. Patterson

Cold Spring Harb Symp Quant Biol 1983 48: 625-631

Access the most recent version at doi:10.1101/SQB.1983.048.01.066

References This article cites 22 articles, 11 of which can be accessed free at:

http://symposium.cshlp.org/content/48/625.refs.html

Article cited in:

http://symposium.cshlp.org/content/48/625\#related-urls

Email alerting

Receive free email alerts when new articles cite this article service sign up in the box at the top right corner of the article or click here

To subscribe to Cold Spring Harbor Symposia on Quantitative Biology go to: http://symposium.cshlp.org/subscriptions 